\title{
Corrosion Inhibition of Steel in Phosphoric Acid by Phenacyldimethyl Sulfonium Bromide and some of its $p$-Substituted Derivatives
}

\author{
S.T. Arab, ${ }^{*}$ A.M. Al-Turkustani \\ Girls' College of Education, General Presidency of Education, \\ Jeddah, Saudi Arabia.
}

Received 3 September 2004; accepted in revised form 13 January 2006

\begin{abstract}
Corrosion inhibition of mild steel in $0.67 \mathrm{M} \mathrm{H}_{3} \mathrm{PO}_{4}$ by phenacyl dimethylsulfonium bromide and six of its $p$-substituted derivatives was studied using different chemical, electrochemical and scanning electron microscopy techniques. The order of increasing inhibition efficiency was correlated with its $p$-substituted through Hammett relation.

Potentiodynamic polarization curves indicated that the compounds acted primarily as mixed-type inhibitors. Electrochemical impedance spectroscopy showed that the steel dissolution is controlled by charge-transfer mechanism.

The kinetic-thermodynamic model of adsorption isotherm described the experimental findings. Number of active sites, binding constant and change of free energy were computed for all studied compounds. Depending on the inhibitor, it was found that each organic molecule replaced one or two adsorbed water molecules from the steel surface. The adsorption center was suggested to be the $\pi$ electrons of the phenyl ring, and a flat configuration adsorption of the molecule may occur.
\end{abstract}

Keywords: corrosion, inhibition, mild steel, sulphomium compounds, electrochemical methods.

\section{Introduction}

Phosphoric acid is a major chemical product which has many important uses, especially in the production of fertilizers. Most of the acid is produced from phosphate rocks and acid solution of $\mathrm{H}_{2} \mathrm{SO}_{4}$ or $\mathrm{HCl}$. Crude $\mathrm{H}_{3} \mathrm{PO}_{4}$ from the attack stage is filtered and concentrated in evaporation units [1]. There is a great need to protect steel material used in phosphoric acid industry from corrosion.

\footnotetext{
* Corresponding author. E-mail address: k_imran2000sa@yahoo.co.uk
} 
Little work appears to have been done on the inhibition of steel in $\mathrm{H}_{3} \mathrm{PO}_{4}$ solutions [2-7]. Fouda et al. [2] studied some quaternary ammonium compounds as corrosion inhibitors for mild steel in $50 \% \mathrm{H}_{3} \mathrm{PO}_{4}$. It was found that the mechanism of corrosion of mild steel in $\mathrm{H}_{3} \mathrm{PO}_{4}$ did not change with increasing acid concentration. Zakvi and Metha [3] studied the corrosion of mild steel in acid medium containing an extract of $0.5 \mathrm{~g} / \mathrm{L}$ mahasudarshana churna (powder) using potentiostatic polarization and transient linear polarization resistance techniques. Hettiarachchi et al. [4] studied the effectiveness of phthalocyanines as corrosion inhibitors for steel in $\mathrm{H}_{3} \mathrm{PO}_{4}$. It was found that water-soluble tetra sulfo-phthalocyanines are very poor corrosion inhibitors. Jianguo et al. [5], proposed the use of polyvinyl, pyrolidone and polyethylenimine as inhibitors for the corrosion of low-carbon steel in $\mathrm{H}_{3} \mathrm{PO}_{4}$. Recently the performance and inhibition characteristics of thiosemicarbazones as corrosion inhibitors for steel in $\mathrm{H}_{3} \mathrm{PO}_{4}$ using different techniques were studied. A correlation between protection efficiencies and molecular structure of the compounds was elucidated [6].

Corrosion inhibition by sulphur containing compounds is usually more effective than the corresponding nitrogen compounds. This is because sulphur is better electron donor than nitrogen, thus the compounds adsorb well on metal surface. Sulphoxides and sulphonium are recommended as inhibitors in acids mainly sulphuric acid solutions [7-11].

Table 1. Structure, molecular weight and melting point of the studied compounds.

\begin{tabular}{|c|c|c|c|c|}
\hline Symbol & Compound name & Structure & $\begin{array}{c}\text { Molecular } \\
\text { weight }\end{array}$ & $\begin{array}{c}\text { Melting } \\
\text { point }\left({ }^{\circ} \mathrm{C}\right)\end{array}$ \\
\hline A & $\begin{array}{c}\text { Phenacyl dimethyl sulfonium } \\
\text { bromide }\end{array}$ & & 261.188 & 157.0 \\
\hline B & $\begin{array}{l}\text { 4-Methylphenacyl dimethyl } \\
\text { sulfonium bromide }\end{array}$ & & 275.300 & 111.0 \\
\hline $\mathrm{C}$ & $\begin{array}{l}\text { 4-Chlorophenacyl dimethyl } \\
\text { sulfonium bromide }\end{array}$ & & 295.500 & 140.0 \\
\hline $\mathrm{D}$ & $\begin{array}{l}\text { 4-Bromophenacyl dimethyl } \\
\text { sulfonium bromide }\end{array}$ & & 339.956 & 96.6 \\
\hline $\mathrm{E}$ & $\begin{array}{l}\text { 4-Nitrophenacyl dimethyl } \\
\text { sulfonium bromide }\end{array}$ & & 320.192 & 100.6 \\
\hline $\mathrm{F}$ & $\begin{array}{l}\text { 4-Methoxy phenacyl } \\
\text { dimethyl sulfonium bromide }\end{array}$ & & 291.214 & 138.2 \\
\hline
\end{tabular}

In the present study the effect of phenacyl dimethyl sulfonium bromides in 0.67 $\mathrm{M}$ of $\mathrm{H}_{3} \mathrm{PO}_{4}$ is investigated by chemical, electrochemical and scanning electron 
microscopy methods. Inhibition mechanism will be evaluated by electrochemical measurements in the absence and presence of various concentrations of the studied compounds, and the effect of substitution in the benzene ring in $p-$ position from Hammett function will be obtained.

\section{Experimental}

The effect of phenacyl dimethylsulfonium bromides on the dissolution process of commercial mild steel in $0.67 \mathrm{M} \mathrm{H}_{3} \mathrm{PO}_{4}$ was studied by (i) chemical methods (hydrogen evolution and mass loss), (ii) electrochemical methods (polarization and impedance spectroscopy), and (iii) scanning electron microscopy analysis.

Sulfonium compounds were prepared by heating a mixture of the appropriate 2bromoacetyl derivatives $(0.1 \mathrm{~mol})$ and dimethyl sulphide $(7.5 \mathrm{~mL}$ of $0.1 \mathrm{~mol})$ in methanol $(50 \mathrm{~mL})$ under reflux for 30 minutes $[7,12,13]$. The solvent was removed under reduced pressure in a rotatory evaporator. The solid products were collected by filtration, washed with methanol and dried. Recrystallization from methanol afforded the corresponding methyl sulfonium bromides as shown in Table 1, powdered using quartz mortar, and their purity was checked by measuring their melting points.

Table 1 gives the structure, molecular weight and melting points of the used sulfonium compounds in the study.

The used mild steel has the following chemical composition:

Table 2. Chemical composition of mild steel specimen.

\begin{tabular}{|c|c|c|c|c|c|c|c|c|c|c|}
\hline $\mathbf{F e}$ & $\mathbf{C}$ & $\mathbf{M n}$ & $\mathbf{P}$ & $\mathbf{M o}$ & $\mathbf{A l}$ & $\mathbf{S n}$ & $\mathbf{V}$ & $\mathbf{N b}$ & $\mathbf{N i}$ & $\mathbf{C u}$ \\
\hline 98.86 & 0.17 & 0.057 & 0.011 & 0.002 & 0.011 & 0.005 & 0.004 & 0.007 & 0.027 & 0.043 \\
\hline
\end{tabular}

Before measurements, specimens were polished first with a series of emery papers of type (231 Qwetordry Imperical Paple aesoc), starting with a coarse one and proceeding in steps to fine grade $[14,15]$. Then the samples were thoroughly washed with deionized water and with acetone (A.R.), dried by a stream of air. The sample was then immediately immersed in the test solution. Reproducible results were obtained by using this method of cleaning. All studies were carried out at constant temperature of $30 \pm 0.02{ }^{\circ} \mathrm{C}$ using an ultrathermostat (Julabo U3 No. 8311). In each new study, the measurement of the sample area was done.

The chemical study was carried out using sample vessel which has the same form as that described by Mylius [16]. The specimen used was in the form of $5.0 \mathrm{~cm}$ rod with surface area of $17.28 \mathrm{~cm}^{2}$. While the polarization curves were determined over a wide range of electrode potentials using the usual electrolytic cell as described before [14,15] and AMEL- potentiostat Mod.533, Italy, with 7 ranges from $1 \mu \mathrm{A}$ to $1 \mathrm{~A}$ and positive feed-back for IR drop compensation, the electrochemical impedance was determined with a working steel electrode of cross section $0.5 \mathrm{~cm}$. The electrochemical impedance spectroscopy measurements were carried out using (ACM Gill AC) connected to a Samsung computer (Bridge DVD ASUS 8X max). 
For morphological studies, the samples were prepared and treated as described before and immersed in the test solution for 45 minutes, then SEM analysis was carried out using Leitz METALLUX 3 scanning microscopy (WETZLAR, Germany), with magnification $(500 \times)$.

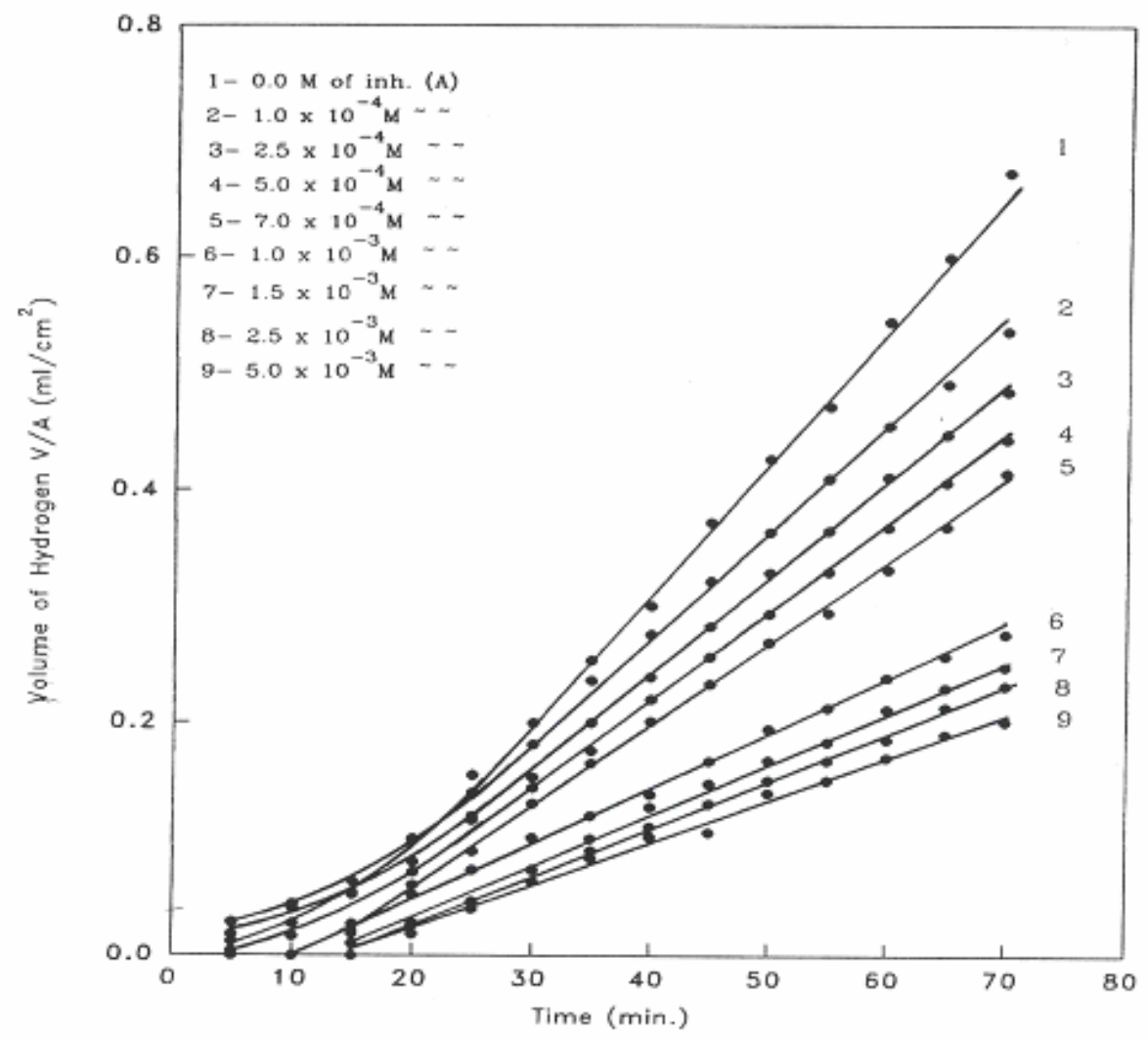

Figure 1. Volume of hydrogen / time curves of mild steel in $2.0 \mathrm{~N} \mathrm{H}_{3} \mathrm{PO}_{4}$ containing different concentrations of inhibitor (A) at $30^{\circ} \mathrm{C}$.

\section{Results and discussion}

\section{a. Chemical study}

Figs. 1 and 2 show the plots of hydrogen volume with time for mild steel sample in $0.67 \mathrm{M} \mathrm{H}_{3} \mathrm{PO}_{4}$ solutions in the absence and presence of different concentrations of compounds $\mathrm{A}$ and $\mathrm{F}$ at $30^{\circ} \mathrm{C}$. When the concentration of the sulfonium bromides increases, the rate of hydrogen evolution (the slope of the straight lines) is decreased, i.e., the corrosion rate of mild steel decreases, indicating inhibition of the corrosion process. An induction period was shown in some cases at the beginning of mild steel exposure, which could be due to the reaction between the acid and the air formed oxide film [17]. It was found that the duration of the induction period depends on the acid concentration, on the sample and on the inhibitor concentration. In $\mathrm{H}_{3} \mathrm{PO}_{4}$ the induction period is more pronounced due to its lower acidity.

The inhibition efficiency was calculated from hydrogen evolution method (Inh. ${ }_{\mathrm{H} \%}$ ) and mass loss method (Inh. ${ }_{\mathrm{M}} \%$ ) using the following two equations $[14,15,17-20]$ : 


$$
\begin{gathered}
\text { Inh. } \mathrm{H}^{\%}=100\left(1-\mathrm{R} / \mathrm{R}_{\mathrm{O}}\right) \\
\text { Inh. }_{\mathrm{M}^{\%}} \%=100\left(1-\mathrm{R}^{\prime} / \mathrm{R}_{\mathrm{O}}{ }_{\mathrm{O}}\right)
\end{gathered}
$$

where $R_{0}$ and $R$ are the rates of hydrogen evolution, and $\mathrm{R}_{\mathrm{o}}$ and $\mathrm{R}^{\prime}$ represent the rates of mass-loss in the absence and in the presence of the studied compounds, respectively. Table 3 shows the inhibition efficiency (Inh.\%) obtained from the studied compounds in $0.67 \mathrm{M} \mathrm{H}_{3} \mathrm{PO}_{4}$. All these compounds show the same behaviour except compound $\mathrm{D}$ which gave an acceleration of corrosion at low concentrations.

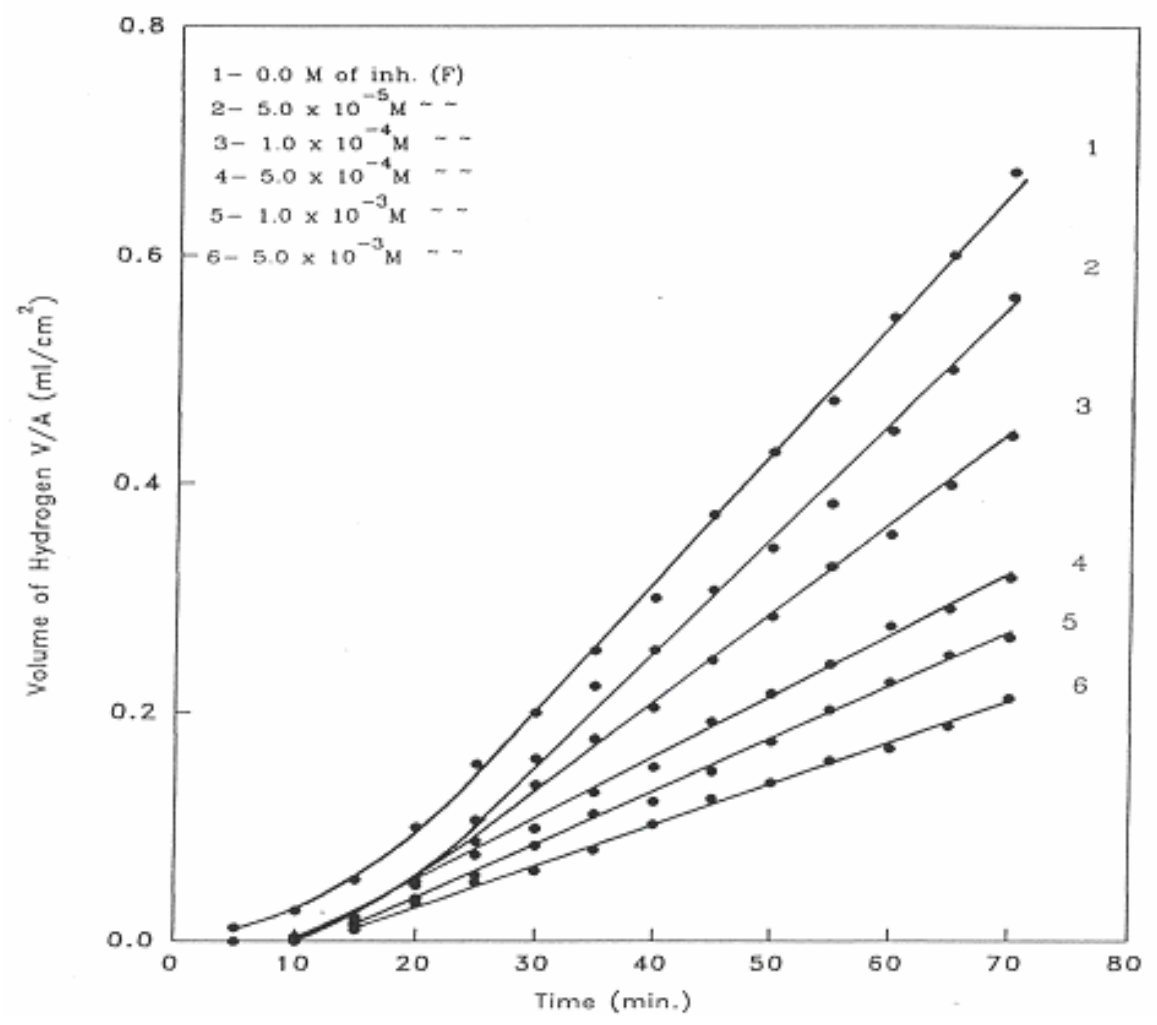

Figure 2. Volume of hydrogen / time curves of mild steel in $2.0 \mathrm{~N} \mathrm{H}_{3} \mathrm{PO}_{4}$ containing different concentrations of inhibitor $(\mathrm{F})$ at $30^{\circ} \mathrm{C}$.

The dual action stimulating corrosion in low concentration $<1.0 \times 10^{-4} \mathrm{M}$ and inhibiting in higher concentrations was also obtained before in some organic compounds [20-24]. They related this behaviour to an oxidative tendency of surface chelates, which takes place until the chelate is adsorbed. If charge transfer occurs with the adsorption of a complex ion, the inhibitor will function as a stimulator. In this study, compound $\mathrm{D}$, in which bromo atom in $p$-position of the benzene ring is present, the effect of electron-donating and electronwithdrawing properties of halogens could be the cause of the dual behaviour of this compound plus its larger size comparing it with the chloro atom in compound C [25]. 
Table 3. Inhibition efficiency for corrosion of mild steel in $0.67 \mathrm{M} \mathrm{H}_{3} \mathrm{PO}_{4}$ solution containing different concentrations of studied compounds at $30{ }^{\circ} \mathrm{C}$.

\begin{tabular}{|c|c|c|c|c|c|c|c|c|c|c|}
\hline \multirow{2}{*}{$\begin{array}{c}\text { Compound } \\
\text { Symbol }\end{array}$} & \multicolumn{2}{|c|}{$5.0 \times 10^{-5}$} & \multicolumn{2}{|c|}{$1.0 \times 10^{-4}$} & \multicolumn{2}{|c|}{$5.0 \times 10^{-4}$} & \multicolumn{2}{|c|}{$1.0 \times 10^{-3}$} & \multicolumn{2}{|c|}{$5.0 \times 10^{-3}$} \\
\hline & Inh. $_{\mathrm{H}} \%$ & Inh. ${ }_{\mathrm{M}} \%$ & Inh. $_{{ }_{H}} \%$ & ${ }^{\text {Inh. }}{ }_{M} \%$ & ${ }_{{ }_{H}}{ }^{\%}$ & ${ }^{\text {Inh. }}{ }^{\%}$ & Inh. $_{\mathrm{H}} \%$ & Inh. ${ }_{\mathrm{M}} \%$ & Inh. $_{\mathrm{H}} \%$ & Inh. ${ }_{M} \%$ \\
\hline A & - & - & 18.76 & 13.72 & 31.50 & 26.99 & 58.85 & 57.97 & 68.32 & 68.76 \\
\hline B & 11.55 & 11.06 & 28.32 & 28.76 & 42.39 & 42.48 & 66.28 & 66.50 & 84.25 & 84.82 \\
\hline $\mathrm{C}$ & 8.85 & 7.08 & 19.12 & 13.27 & 23.97 & 21.05 & 58.94 & 56.31 & 68.76 & 68.05 \\
\hline D & -38.05 & -40.27 & 1.77 & 1.33 & 13.63 & 11.50 & 24.51 & 23.89 & 45.58 & 46.46 \\
\hline E & 19.56 & 19.91 & 40.35 & 40.71 & 56.64 & 55.31 & 71.06 & 71.02 & 84.78 & 84.69 \\
\hline $\mathrm{F}$ & 14.69 & 7.96 & 30.89 & 29.65 & 52.12 & 50.89 & 58.94 & 57.83 & 68.14 & 66.77 \\
\hline
\end{tabular}

At the higher concentrations the calculated values from hydrogen evolution method [HEM] and mass-loss method [MLM], are in good agreement for all the studied compounds. At low concentrations the observed difference may be explained by a decrease in the volume of collected hydrogen due to the loss of gas by dissolution in the solutions.

Sulfonium compounds in aqueous acidic solutions may exist in cationic form [25] and adsorb through electrostatic interaction between the positively charged sulfonium cations and the negatively charged metal surface [26]. Also, the $\pi$ electrons of the benzene ring and the nature of the substituents present in the inhibitor molecule play a significant role in influencing the extent of adsorption [27].

The order of increasing inhibition efficiency (Inh.\%) of substituted sulfonium bromides in $0.67 \mathrm{M} \mathrm{H}_{3} \mathrm{PO}_{4}$ solutions of the studied compounds is almost as:

$$
\mathrm{E}>\mathrm{F}>\mathrm{B}>\mathrm{A} \simeq \mathrm{C}>\mathrm{D}
$$

Compound $\mathrm{E}$ (which has nitro group in para position in the benzene ring), gave a higher inhibition efficiency than compounds $\mathrm{B}$ and $\mathrm{F}$. This may be attributed to an interaction between this compound and the formed $\mathrm{Fe}\left(\mathrm{H}_{2} \mathrm{PO}_{4}\right)_{2}$ on the metal surface [28].

Linear free energy relationship (LFER) has been used to correlate the inhibition efficiency of organic compounds with Hammett substituent constant $\sigma$, which is given by [29-32]:

$$
\log \left(R_{\mathrm{O}} / \mathrm{R}\right)=(-\rho \sigma)
$$

where $\mathrm{R}_{0}$ and $\mathrm{R}$ are the corrosion rate in the absence and presence of substitution at a certain concentration of the inhibitors, and $\rho$ is the reaction constant [31]. The electron donating substituents have negative $\sigma$ values and those attracting electrons from the reaction center have positive $\sigma$ values. Thus, $\sigma$ is a relative measure of the electron density at the reaction center. The slope of the plot of log $\left(R_{0} / R\right)$ vs. $\sigma$ is $\rho$ and its sign indicates whether the process is inhibited by an increase or a decrease of electron density at reaction center. The magnitude of $\rho$ indicates the relative sensitivity of the inhibition process to electronic effects. 


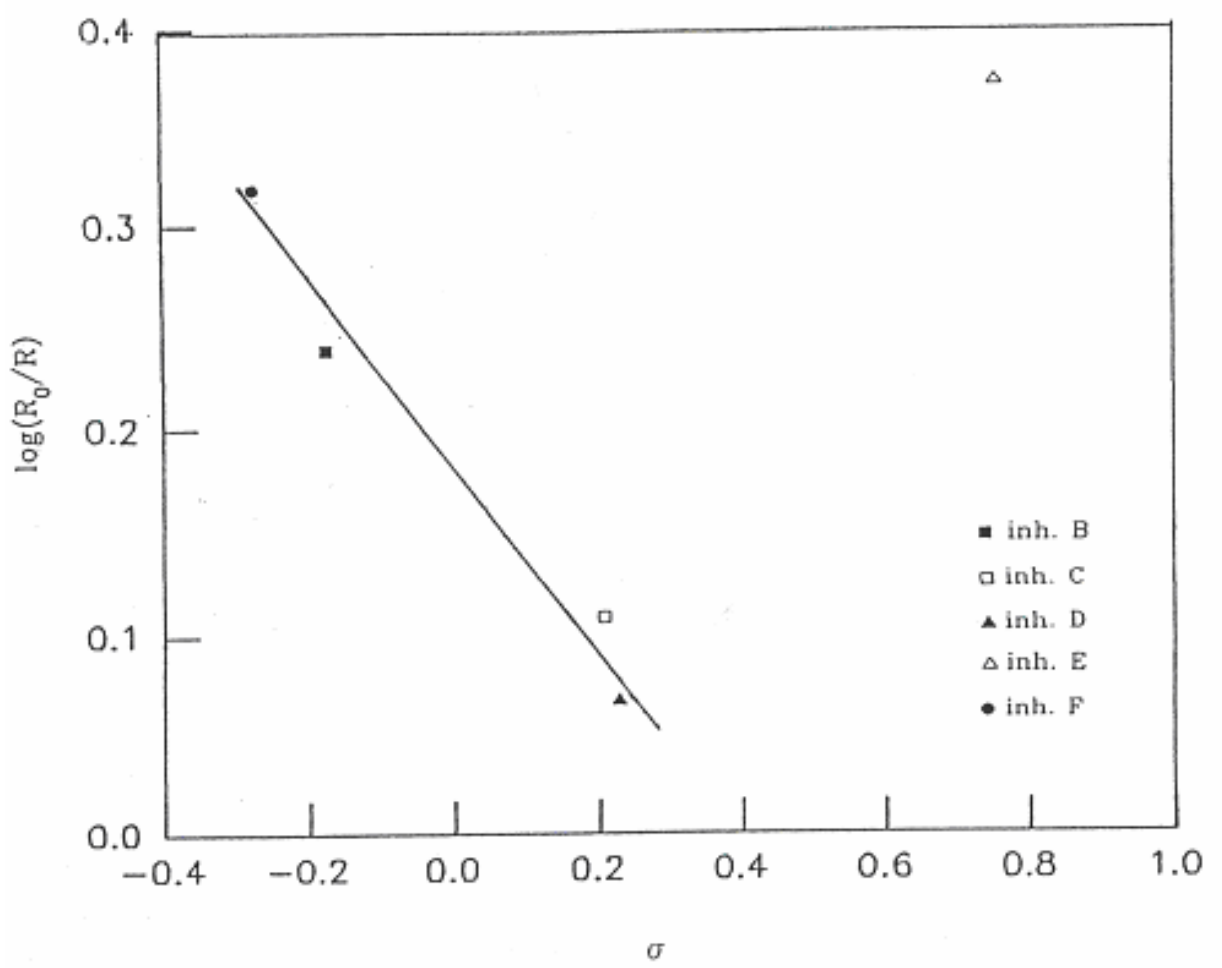

Figure 3. Relationship between inhibitor $(\log \mathrm{R} 0 / \mathrm{R})$ and Hammett constants of compounds $\mathrm{B}, \mathrm{C}, \mathrm{D}, \mathrm{E}$ and $\mathrm{F}$ in $2.0 \mathrm{~N} \mathrm{H}_{3} \mathrm{PO}_{4}$ at $30^{\circ} \mathrm{C}$.

The applicability of Eq. (3) is shown in Fig. 3. The abnormal behaviour of the nitro compound by giving a high inhibition efficiency compared to the other studied compounds is obtained. This was previously reported [32]. Such behaviour may be attributed to an alternative mode of adsorption of the nitro derivative. The lone electron pair on the oxygen atoms of the nitro group may act as an active center for adsorption in $\mathrm{H}_{3} \mathrm{PO}_{4}$ solution. The low value of slope $(\rho=$ 0.462) is attributed to weak electronic resonance occurring between the substituted group and the benzene ring in the molecule. Thus a weak dependence of adsorption character of the reaction center on the electron density of the ring is present.

\section{Adsorption isotherms}

The variation in the $\mathrm{Inh}_{{ }_{\mathrm{H}}} \%$ with the logarithm of the molar concentration of the studied compounds on mild steel in $0.67 \mathrm{M} \mathrm{H}_{3} \mathrm{PO}_{4}$ is represented in Fig. 4. All the curves have nearly S-shaped adsorption isotherm. This indicates that these compounds inhibit the acid corrosion of mild steel by adsorption at the mild steel surface in $\mathrm{H}_{3} \mathrm{PO}_{4}$ acid solutions. The obtained figures indicate one step of adsorption [33] for the studied compounds, except compound B, which shows two adsorption steps.

Based on the obtained data, it is assumed that the inhibition of mild steel corrosion in $0.67 \mathrm{M} \mathrm{H}_{3} \mathrm{PO}_{4}$ solutions by the studied compounds occurs by adsorption on the appropriate sites at the electrode surface by the $\pi$ electrons on the phenyl ring. 


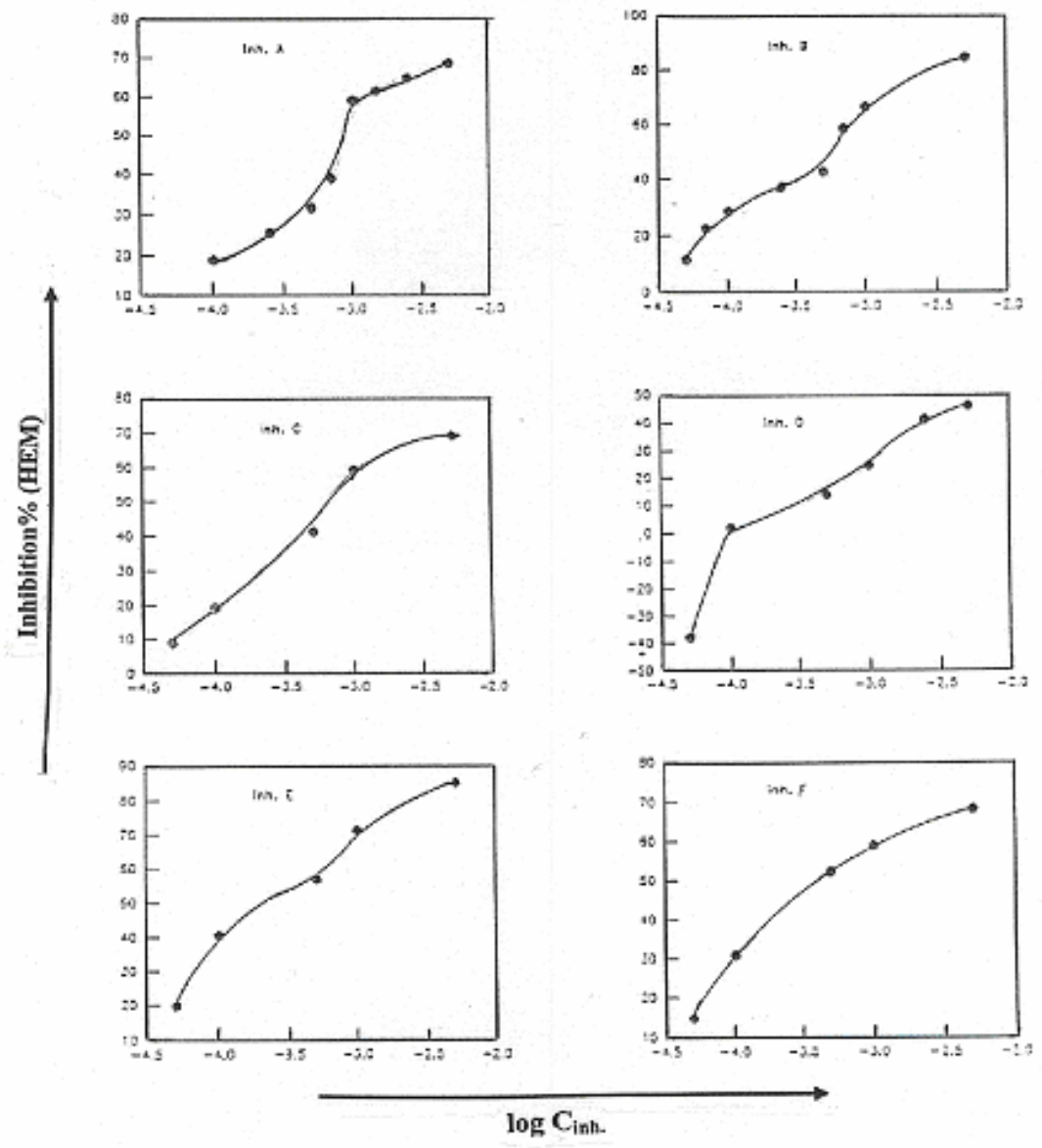

Figure 4. Variation of inhibition efficiency (HEM) with the logarithm of the concentration of the studied inhibitors for mild steel in $0.67 \mathrm{M} \mathrm{H}_{3} \mathrm{PO}_{4}$ at $30^{\circ} \mathrm{C}$.

The adsorption center was suggested to be the $\pi$ electrons of the phenyl ring according to a proposed scheme (Fig. 5).

The recorded data in Table 3 were used to determine the suitable isotherm fitting on the surface coverage in relation to the inhibitor concentration. An excellent fit was obtained for the compounds using the kinetic-thermodynamic model (Eq.4) [34,35]:

$$
\log (\Theta /(1-\Theta))=\log \dot{K}^{\prime}+\mathrm{y} \log \mathrm{C}
$$

where $K$ is a constant related to the binding constant, $K$, by the following relationship:

$$
\mathrm{K}=\mathrm{K}^{(1 / \mathrm{y})}
$$

where $y$ is the number of the inhibitor molecules occupying one active site, and $1 / y=x$ represents the number of active sites of the surface occupied by one molecule of the inhibitor. Values of $1 / y<$ unity mean that a given inhibitor molecule will occupy more than one active site. Large values of the binding constant mean better inhibition efficiency of a given compound (i.e., stronger 
electrical interaction for the adsorbing molecules at the surface of the metal). Small values of the binding constant, however, indicate that such interactions by the adsorbing molecules and the metal surface are weaker, denoting that the molecules are easily removed by the solvent molecules from the surface [34,35].

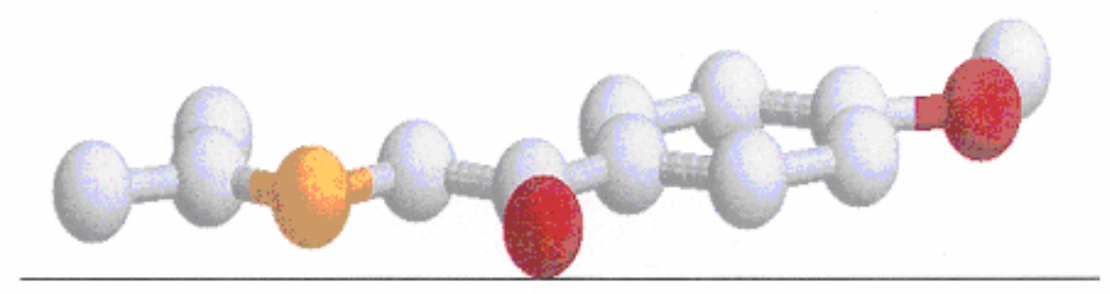

Figure 5. Suggested model for the adsorption of sulfonium ion on steel surface.

Fig. 6 shows $\log (\Theta / 1-\Theta)$ vs. $\log C$ for the studied inhibitors. Straight lines of a slope between 1.0 and 2.0 were found for inhibitors B and E. Table 4 gives the adsorption parameters calculated with the kinetic-thermodynamic model. The slopes between 1.0 and 2.5 may be explained as follows: the metal surface in aqueous solution is always covered with adsorbed water dipoles [36]. Hence the adsorption of inhibitor molecules from aqueous solutions is a substitution process [37]:

$$
\text { Inhibitor }_{(\text {soln })}+\mathrm{xH}_{2} \mathrm{O}_{(\text {ads })} \leftrightarrow \text { Inhibitor }_{(\text {ads })}+\mathrm{xH}_{2} \mathrm{O}_{\text {(soln) }}
$$

so when the number of substituted $\mathrm{H}_{2} \mathrm{O}$ will be $\mathrm{x} \simeq 1$, i.e., one water molecule is replaced by one molecule of inhibitor.

Values of $\mathrm{x}>$ unity mean that the number of substituted $\mathrm{H}_{2} \mathrm{O}$ will be $\mathrm{x} \simeq 2$ or $\mathrm{x} \simeq$ 3 , i.e., two or three water molecules are replaced by one molecule of inhibitor. The obtained values of $\mathrm{K}$ for the studied compounds are in the same order of the inhibition efficiency.

The value of constant $\mathrm{K}$ is related to the standard free energy of adsorption, $\Delta \mathrm{G}_{\mathrm{ads}}^{\circ}$, by the following equation $[24,38]$ :

$$
\mathrm{K}=1 / 55.5 \exp \left(-\Delta \mathrm{G}^{\mathrm{o}} \text { ads. } / \mathrm{RT}\right)
$$

where 55.5 is the concentration of water at electrode / electrolyte interface in mol.L $\mathrm{L}^{-1}$.

Values of $\Delta \mathrm{G}_{\text {ads. }}^{\circ}$ obtained for the compounds in $\mathrm{H}_{3} \mathrm{PO}_{4}$ are reported in Table 4. Negative values of $\Delta \mathrm{G}_{\text {ads. }}^{\circ}$ are characteristic features of strong adsorption [3436], which indicate that adsorption of the studied molecules occurs in a flat configuration [39]. 

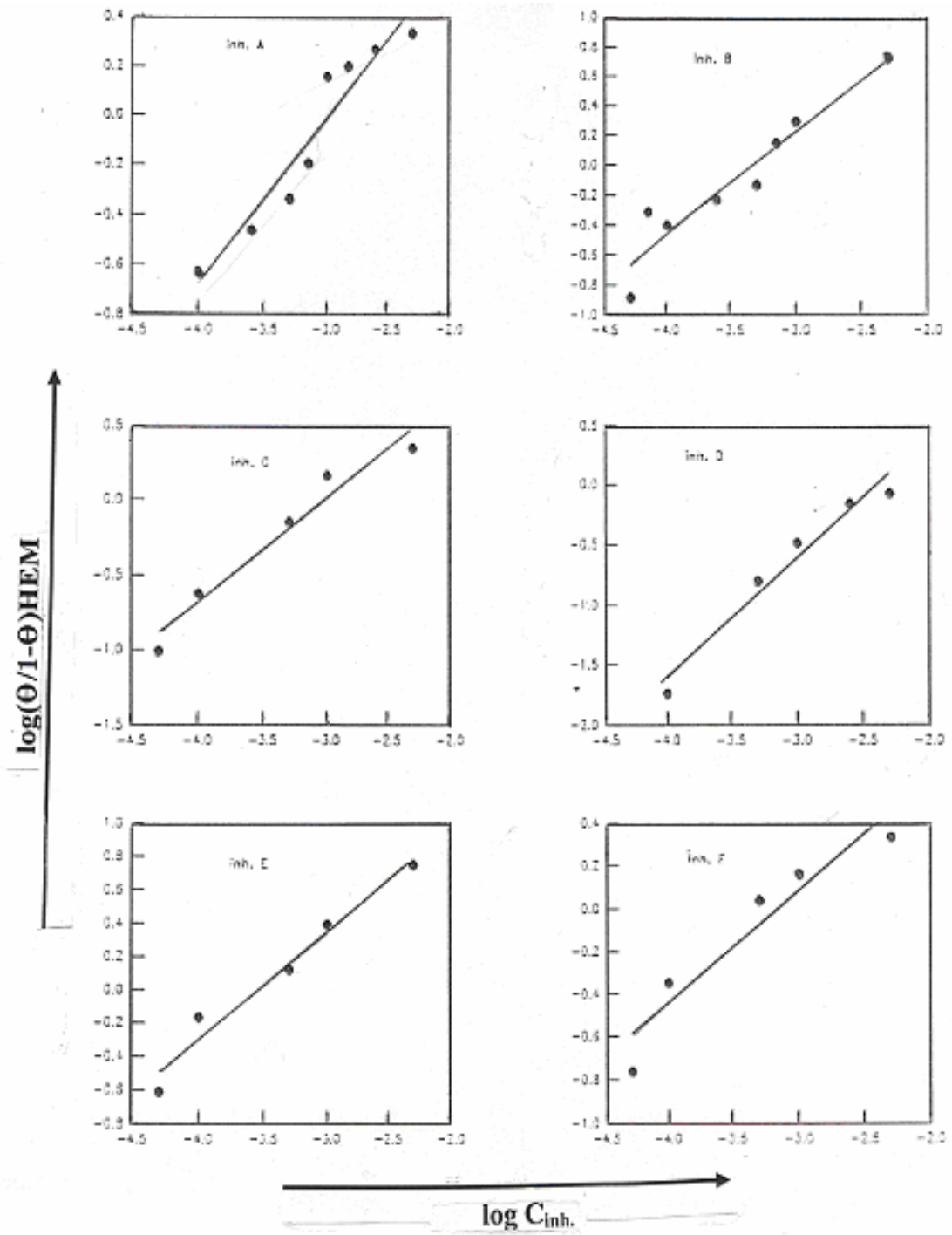

Figure 6. Variation of logarithm $(\theta / 1-\theta)$ HEM with the logarithm of the concentration of the studied inhibitors for mild steel in $0.67 \mathrm{M} \mathrm{H}_{3} \mathrm{PO}_{4}$ at $30^{\circ} \mathrm{C}$.

Table 4: Number of active site values of the binding constant, and standard free energies of adsorption obtained from the kinetic-thermodynamic used for sulfonium bromides in $0.67 \mathrm{M}^{\circ} \mathrm{H}_{3} \mathrm{PO}_{4}$ at $30{ }^{\circ} \mathrm{C}$.

\begin{tabular}{cccc}
\hline \multirow{2}{*}{$\begin{array}{c}\text { Compound } \\
\text { Symbol }\end{array}$} & \multicolumn{3}{c}{ Kinetic-thermodynamic-model } \\
\cline { 2 - 4 } $\mathrm{A}$ & $1 / \mathrm{y}$ & $\mathrm{K}\left(\mathrm{M}^{-1}\right)$ & $\Delta \mathrm{G}_{\text {ads. }}^{\circ}(\mathrm{kJ} / \mathrm{mol})$ \\
\hline $\mathrm{B}$ & 1.7057 & 1095.9 & -27.76 \\
$\mathrm{C}$ & 1.310 & 1763.5 & -28.96 \\
$\mathrm{D}$ & 1.353 & 1943.5 & -28.46 \\
$\mathrm{E}$ & 1.875 & 4404.9 & -23.38 \\
$\mathrm{~F}$ & 2.499 & 1817.2 & -31.27 \\
\hline
\end{tabular}




\section{b. Electrochemical study}

Fig. 7 and 8 show the polarization curves of mild steel in $0.67 \mathrm{M} \mathrm{H}_{3} \mathrm{PO}_{4}$ solution in the absence and presence of different concentrations of compounds $\mathrm{A}$ and $\mathrm{F}$ at $30{ }^{\circ} \mathrm{C}$. Table 5 shows the electrochemical parameters: corrosion potential $\left(\mathrm{E}_{\text {corr }}\right)$, corrosion current $\left(\mathrm{I}_{\text {corr }}\right)$, anodic and cathodic Tafel slopes $\left(\beta_{\mathrm{a}}\right.$ and $\left.\beta_{\mathrm{c}}\right)$, and the inhibition efficiencies (Inh. p \%).

The inhibition percentage of corrosion of mild steel from polarization measurements, Inh. $\mathrm{p} \%$, was calculated from [40]:

$$
\text { Inh. } \mathrm{P}^{\%}=\left(1-\mathrm{I}_{\text {cor. }} / \mathrm{I}_{\text {cor. }}^{\circ}\right) \times 100
$$

where $\mathrm{I}_{\text {cor }}^{\circ}$ and $\mathrm{I}_{\text {cor }}$ are the corrosion current density values without and with inhibitor, respectively .

At low inhibitor concentrations the inhibition efficiency calculated from polarization measurements for all compounds is always higher than that obtained from chemical measurements [41,42]. This difference can be attributed to the fact that MLM gives average corrosion rates, whereas electrochemical methods give instantaneous corrosion rates, as reported before $[41,42]$.

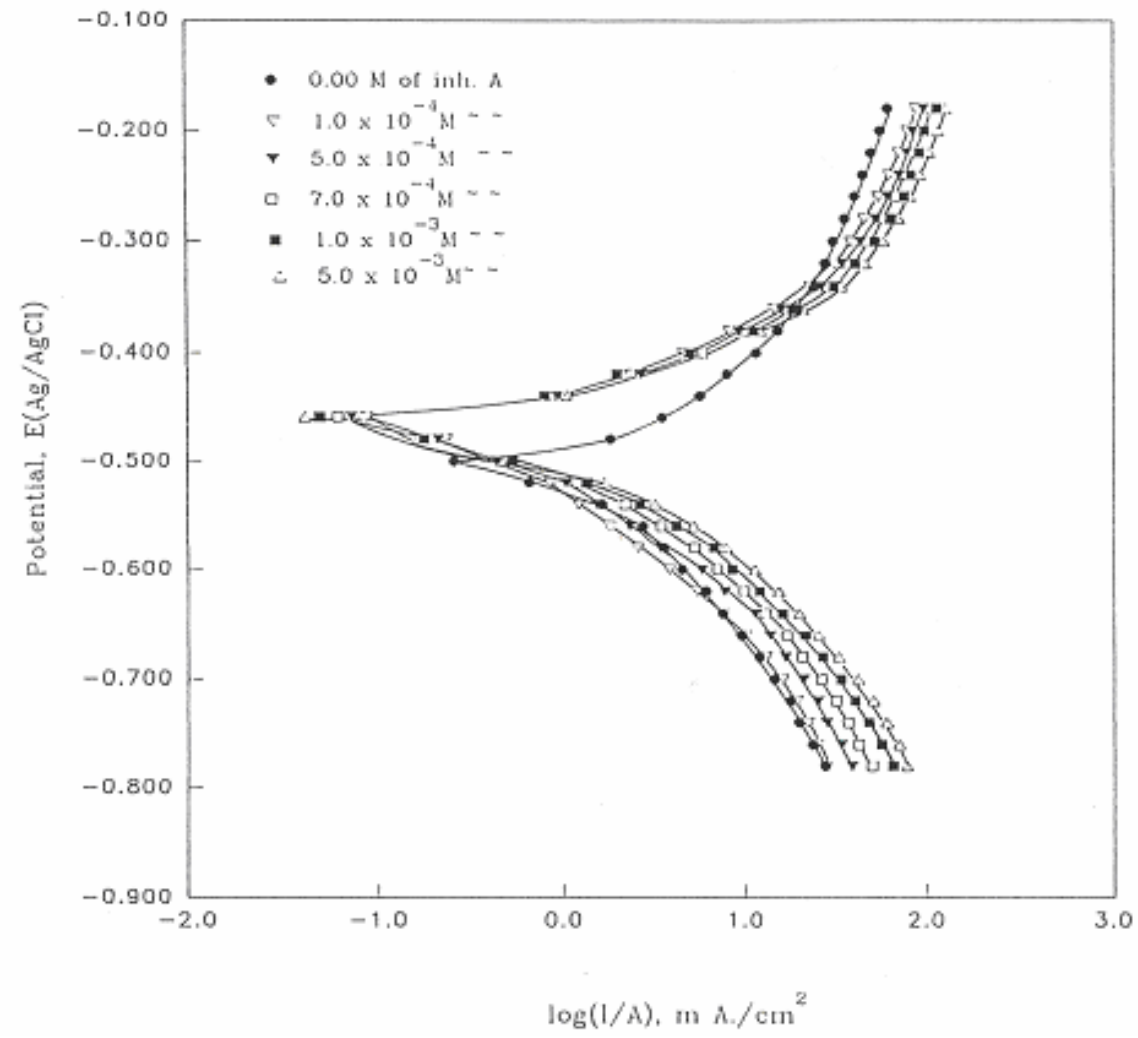

Figure 7. Polarization curves of mild steel in $2.0 \mathrm{~N} \mathrm{H}_{3} \mathrm{PO}_{4}$ in the absence and presence of different concentrations of inhibitor (A) at $30^{\circ} \mathrm{C}$. 
Good consistency is observed at high concentrations, probably because the higher bulk concentration of the compound leads to an increase in adsorption and blocking of the metal surface [17].

The corrosion potential $\left(\mathrm{E}_{\text {corr }}\right)$ values are shifted to more anodic potential than of the blank solution, except compound $A$ which gives constant values of $E_{\text {corr }}$ at various concentrations.

Table 5: Electrochemical parameters and inhibition percentages of mild steel sample corrosion in $0.67 \mathrm{M} \mathrm{H}_{3} \mathrm{PO}_{4}$ in the absence and presence of different concentrations of compounds (A-F) at $30{ }^{\circ} \mathrm{C}$.

\begin{tabular}{|c|c|c|c|c|c|c|c|c|}
\hline \multicolumn{2}{|c|}{$\begin{array}{l}\text { Compound } \\
\text { sympol }\end{array}$} & $\begin{array}{c}C_{M} \\
\text { [Inh.] }\end{array}$ & $\begin{array}{l}-E o . c \\
(V)\end{array}$ & $\begin{array}{c}-E_{\text {corr. }} \\
\text { (V) }\end{array}$ & $\begin{array}{c}I_{\text {corr. }} \\
\left(m A . \mathrm{cm}^{-2}\right)\end{array}$ & $\begin{array}{c}\beta_{a} \\
\left(\operatorname{Vdec}^{-1}\right)\end{array}$ & $\begin{array}{c}-\beta_{c} \\
\left(\operatorname{Vdec}^{-1}\right)\end{array}$ & $\operatorname{Inh} \cdot \boldsymbol{P}^{\%}$ \\
\hline \multicolumn{2}{|c|}{ Blank } & 0.0 & 0.593 & 0.480 & 0.595 & 0.070 & 0.085 & --- \\
\hline \multirow{5}{*}{ 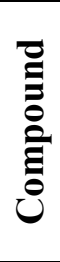 } & \multirow{5}{*}{ 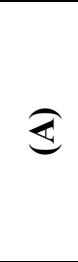 } & $1.0 \times 10^{-4}$ & 0.500 & 0.480 & 0.479 & 0.085 & 0.135 & 19.50 \\
\hline & & $5.0 \times 10^{-4}$ & 0.498 & 0.480 & 0.398 & 0.075 & 0.100 & 33.11 \\
\hline & & $7.0 \times 10^{-4}$ & 0.495 & 0.480 & 0.347 & 0.075 & 0.070 & 41.68 \\
\hline & & $1.0 \times 10^{-3}$ & 0.493 & 0.480 & 0.275 & 0.065 & 0.065 & 53.78 \\
\hline & & $5.0 \times 10^{-3}$ & 0.490 & 0.480 & 0.200 & 0.065 & 0.055 & 66.39 \\
\hline \multirow{5}{*}{ 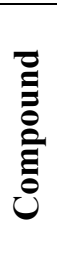 } & \multirow{5}{*}{$\widehat{\theta}$} & $5.0 \times 10^{-5}$ & 0.492 & 0.470 & 0.457 & 0.070 & 0.085 & 23.19 \\
\hline & & $1.0 \times 0^{-4}$ & 0.490 & 0.485 & 0.363 & 0.065 & 0.075 & 38.99 \\
\hline & & $5.0 \times 10^{-4}$ & 0.480 & 0.470 & 0.302 & 0.060 & 0.085 & 49.24 \\
\hline & & $1.0 \times 10^{-3}$ & 0.472 & 0.480 & 0.174 & 0.040 & 0.070 & 70.76 \\
\hline & & $5.0 \times 10^{-3}$ & 0.460 & 0.490 & 0.091 & 0.045 & 0.055 & 84.71 \\
\hline \multirow{5}{*}{ 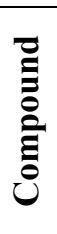 } & \multirow{5}{*}{0} & $5.0 \times 10^{-5}$ & 0.500 & 0.460 & 0.501 & 0.060 & 0.115 & 15.80 \\
\hline & & $1.0 \times 10^{-4}$ & 0.500 & 0.465 & 0.468 & 0.055 & 0.105 & 21.035 \\
\hline & & $5.0 \times 10^{-4}$ & 0.500 & 0.460 & 0.437 & 0.060 & 0.110 & 26.56 \\
\hline & & $1.0 \times 10^{-3}$ & 0.489 & 0.480 & 0.316 & 0.045 & 0.095 & 46.89 \\
\hline & & $5.0 \times 10^{-3}$ & 0.433 & 0.470 & 0.182 & 0.045 & 0.080 & 69.41 \\
\hline \multirow{4}{*}{ 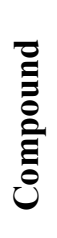 } & \multirow{4}{*}{$\widehat{\theta}$} & $5.0 \times 10^{-5}$ & 0.485 & 0.480 & 0.759 & 0.090 & 0.090 & -27.56 \\
\hline & & $1.0 \times 10^{-3}$ & 0.485 & 0.475 & 0.457 & 0.070 & 0.085 & 23.19 \\
\hline & & $2.5 \times 10^{-3}$ & 0.478 & 0.475 & 0.275 & 0.065 & 0.090 & 53.78 \\
\hline & & $5.0 \times 10^{-3}$ & 0.470 & 0.470 & 0.148 & 0.070 & 0.090 & 74.96 \\
\hline \multirow{5}{*}{ 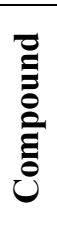 } & \multirow{5}{*}{ 푈 } & $5.0 \times 10^{-5}$ & 0.491 & 0.480 & 0.479 & 0.070 & 0.075 & 19.50 \\
\hline & & $1.0 \times 10^{-4}$ & 0.490 & 0.465 & 0.389 & 0.070 & 0.055 & 33.11 \\
\hline & & $5.0 \times 10^{-4}$ & 0.490 & 0.450 & 0.275 & 0.050 & 0.050 & 53.78 \\
\hline & & $1.0 \times 10^{-3}$ & 0.489 & 0.430 & 0.191 & 0.045 & 0.045 & 67.90 \\
\hline & & $5.0 \times 10^{-3}$ & 0.487 & 0.420 & 0.120 & 0.040 & 0.030 & 79.83 \\
\hline \multirow{5}{*}{ 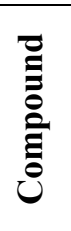 } & \multirow{5}{*}{ E } & $5.0 \times 10^{-5}$ & 0.492 & 0.470 & 0.550 & 0.065 & 0.085 & 7.56 \\
\hline & & $1.0 \times 10^{-4}$ & 0.490 & 0.470 & 0.407 & 0.065 & 0.085 & 31.60 \\
\hline & & $5.0 \times 10^{-4}$ & 0.488 & 0.475 & 0.288 & 0.060 & 0.085 & 51.60 \\
\hline & & $1.0 \times 10^{-3}$ & 0.485 & 0.465 & 0.251 & 0.055 & 0.085 & 57.82 \\
\hline & & $5.0 \times 10^{-3}$ & 0.485 & 0.470 & 0.191 & 0.060 & 0.085 & 67.90 \\
\hline
\end{tabular}


The polarization curves of the studied compounds showed that all the investigated compounds retarded the cathodic and anodic corrosion reactions. This effect is accompanied with a shift in the anodic and cathodic Tafel lines as seen from Figs. 7 and 8 . This means that the studied sulfonium bromides in 0.67 $\mathrm{M} \mathrm{H}_{3} \mathrm{PO}_{4}$ influenced the metal dissolution and hydrogen evolution processes, i.e., act as mixed type inhibitors. This could be attributed to the adsorption of the studied compounds at the cathodic sites of the mild steel surface, leading to a decrease in the exposed area necessary for hydrogen evolution and thus lowering the dissolution rate, as suggested by many researchers $[19,43]$.

c. Electrochemical Impedance Spectroscopy study (EIS)

Fig. 9 shows the Nyquist plots of the studied mild steel sample in $0.67 \mathrm{M} \mathrm{H}_{3} \mathrm{PO}_{4}$ in the absence and presence of $1.0 \times 10^{-3} \mathrm{M}$ sulfonium bromides after $15 \mathrm{~min}$ at $30{ }^{\circ} \mathrm{C}$. The semi-circle type appearance of impedance diagrams indicates that the corrosion of mild steel is mainly controlled by a charge transfer process, and the presence of the inhibition does not affect the dissolution mechanism of mild steel.

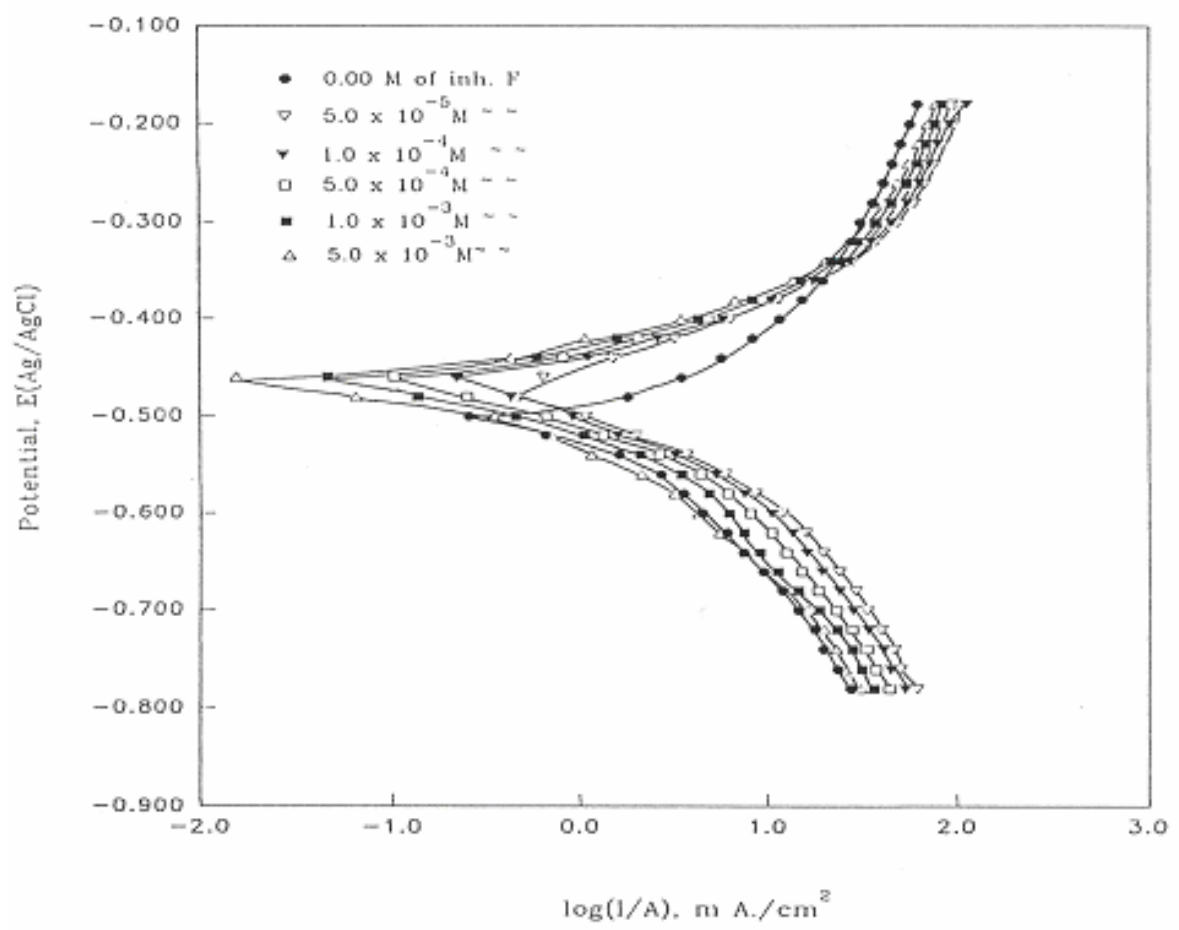

Figure 8. Polarization curves of mild steel in $2.0 \mathrm{~N} \mathrm{H}_{3} \mathrm{PO}_{4}$ in the absence and presence of different concentrations of inhibitor $(\mathrm{F})$ at $30^{\circ} \mathrm{C}$.

The electrochemical parameters $\left(\mathrm{R}_{\mathrm{ct}}\right.$ and $\left.\mathrm{C}_{\mathrm{dl}}\right)$ established from the Nyquist diagram, and the values of inhibition efficiencies (Inh.Rct $\%$ and Inh.Cdl $\%$ ) are given in Table 6.

Inhibition efficiencies were calculated from the following equations [44]: 


$$
\begin{gathered}
\text { Inh. } \mathrm{Rct}^{\%} \%=\left(\mathrm{R}_{\mathrm{cto}}{ }^{-1}-\mathrm{R}_{\mathrm{ct}}{ }^{-1} / \mathrm{R}_{\mathrm{cto}}{ }^{-1}\right) \times 100 \\
\text { Inh. } \mathrm{Cdl}_{\mathrm{d}} \%=\left(\mathrm{C}_{\mathrm{dlo}}-\mathrm{C}_{\mathrm{dl}} / \mathrm{C}_{\mathrm{dlo}}\right) \times 100
\end{gathered}
$$

where $R_{c t o}$ and $R_{c t}$ are the values of charge transfer resistance and $C_{d l o}$ and $C_{d l}$ are the double layer capacitance for mild steel in $0.67 \mathrm{M} \mathrm{H}_{3} \mathrm{PO}_{4}$, without and with inhibitor, respectively. Inhibition efficiencies obtained from $\mathrm{R}_{\mathrm{ct}}$ and $\mathrm{C}_{\mathrm{dl}}$ are in good agreement with those obtained from gasometry and D.C. polarization results.

The charge transfer resistance $\left(\mathrm{R}_{\mathrm{ct}}\right)$ values were calculated from the difference in impedance at lower and higher frequencies, as suggested by Tsura et al. [45]. Table 6 shows that the charge transfer resistance $R_{c t}$ increases in the presence of the studied compounds due to the gradual replacement of water molecules by the adsorption of the studied compound molecules on the metal surface by sulfonium ion.

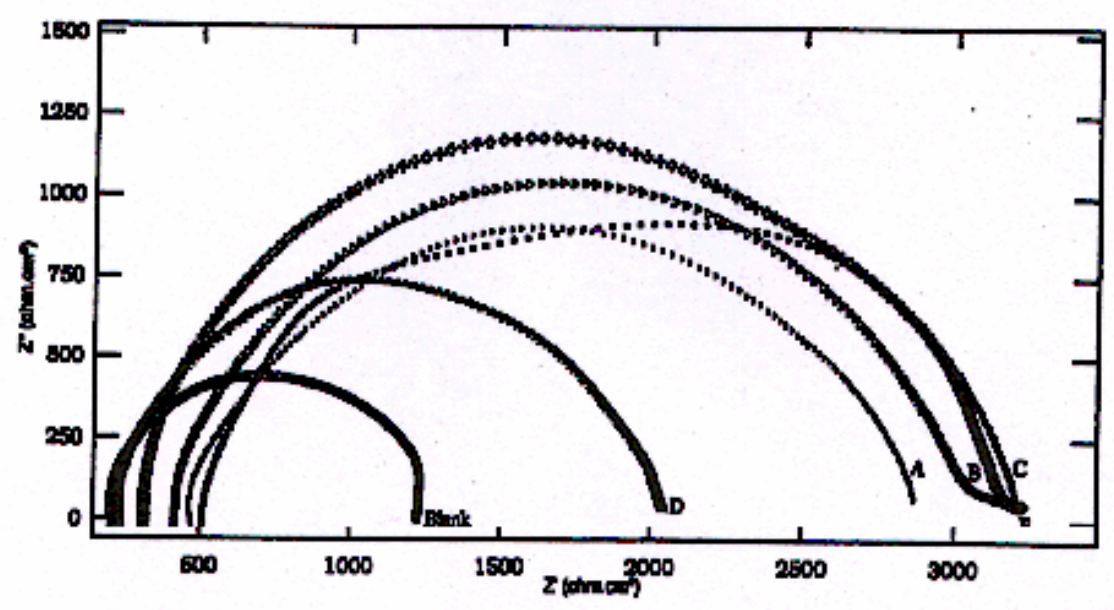

Figure 9. Nyquist plot for mild steel sample corrosion in $0.67 \mathrm{M} \mathrm{H}_{3} \mathrm{PO}_{4}$ in the presence of $1.0 \times 10^{-3} \mathrm{M}$ of the studied compounds at $30^{\circ} \mathrm{C}$.

Table 6: Impedance parameters for the corrosion of mild steel in $0.67 \mathrm{M} \mathrm{H}_{3} \mathrm{PO} 4$ solution containing $1.0 \times 10^{-3} \mathrm{M}$ of studied compounds at $30^{\circ} \mathrm{C}$.

\begin{tabular}{ccccc}
\hline $\begin{array}{c}\text { Compound } \\
\text { Sympol }\end{array}$ & $\begin{array}{c}\mathrm{R}_{\mathrm{ct}} \\
(\mathrm{ohms.cm} 2)\end{array}$ & $\begin{array}{c}\mathrm{C}_{\mathrm{dl}} \\
(\mu \mathrm{F})\end{array}$ & Inh.Rct\% & ${ }^{\mathrm{Inh} .} \mathrm{C}_{\mathrm{dl}} \%$ \\
\hline Blank & $1.059 \times 10^{3}$ & 40205 & ---- & ---- \\
$\mathrm{A}$ & $2.342 \times 10^{3}$ & 3.038 & 54.77 & 27.75 \\
$\mathrm{~B}$ & $2.630 \times 10^{3}$ & 2.311 & 59.72 & 45.04 \\
$\mathrm{C}$ & $2.520 \times 10^{3}$ & 3.667 & 57.96 & 12.79 \\
$\mathrm{D}$ & $1.756 \times 10^{3}$ & 2.910 & 39.67 & 30.80 \\
$\mathrm{~F}$ & $2.822 \times 10^{3}$ & 1.082 & 62.46 & 74.27 \\
\hline
\end{tabular}


The double layer capacitance values are obtained from the following equation $[46,47]$ :

$$
\mathrm{f}\left(-\mathrm{Z}_{\max }\right)=1 / 2 \pi \mathrm{C}_{\mathrm{dl}} \mathrm{R}_{\mathrm{ct}}
$$

\section{d. Scanning Electron Microscopy (SEM)}

It is found from the above experimental data that sulfonium bromides proved good inhibition in $0.67 \mathrm{M} \mathrm{H}_{3} \mathrm{PO}_{4}$, depending on the substituted group in the benzene ring. To confirm the obtained results, electron microscope photographs of mild steel were taken before and after immersion in $0.67 \mathrm{M} \mathrm{H}_{3} \mathrm{PO}_{4}$ solution and in the presence of $1.0 \times 10^{-3} \mathrm{M}$ of $\mathrm{F}$ and $\mathrm{D}$, and $1.0 \times 10^{-5} \mathrm{M}$ of D, [Figs. 10(ae)].

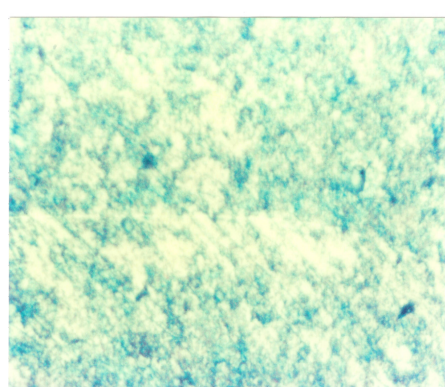

a)

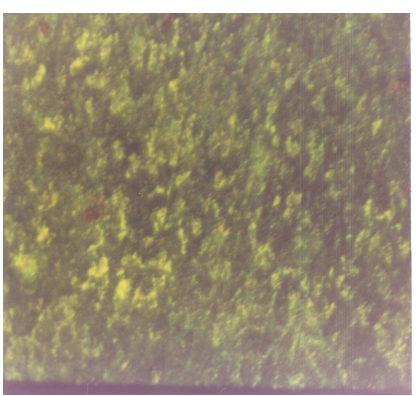

d)

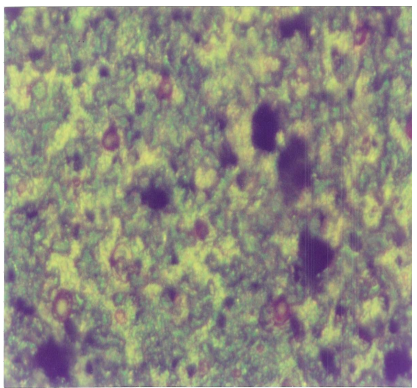

b)

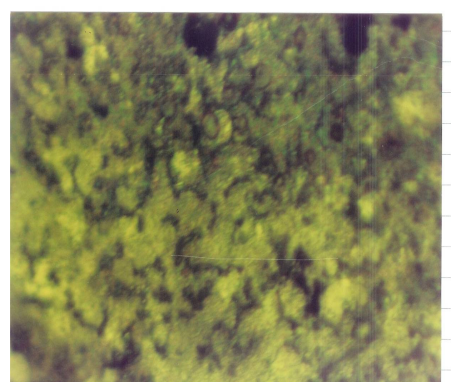

c)

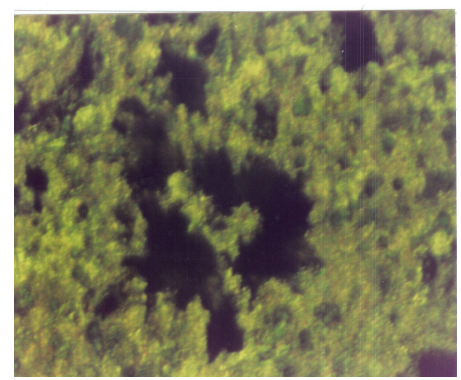

e)

Figure 10 (a-e): SEM photograph of mild steel sample before corrosion and after immersion in $0.67 \mathrm{M} \mathrm{H}_{3} \mathrm{PO}_{4}$ solution and in the presence of $1.0 \times 10^{-3} \mathrm{M}$ of $\mathrm{D}$ and $\mathrm{F}$ and in $1.0 \times 10^{-5} \mathrm{M}$ of $\mathrm{D}$ at $30^{\circ} \mathrm{C}$.

Fig. 10a illustrates the clean surface of studied sample before immersion in the test solution, while Fig. $10 \mathrm{~b}$ illustrates the effect of $0.67 \mathrm{M} \mathrm{H}_{3} \mathrm{PO}_{4}$ solutions on mild steel specimen at $30{ }^{\circ} \mathrm{C}$ after 70 min immersion. A general corrosion with a large shallow pits caused by $\mathrm{H}_{3} \mathrm{PO}_{4}$ on steel surface is present.

On comparing these microphotographs with those in Fig. 10c and 10d it appears that in the presence of $1.0 \times 10^{-3} \mathrm{M}$ of $\mathrm{D}$ and $\mathrm{F}$ some changes in the surface morphology occur due to the presence of the adsorbed layer of inhibitor molecules, and the produced pits on the surface of the steel by $\mathrm{H}_{3} \mathrm{PO}_{4}$ are disappeared by the addition of the studied compounds, which inhibit the 
corrosion. Whereas in Fig. 10e an acceleration of corrosion was observed with $1.0 \times 10^{-5} \mathrm{M}$ of $\mathrm{D}$ which supported the obtained results.

\section{References}

1. T. Sydberger, S. Nordin, Corrosion 34 (1978) 16.

2. Fouda, H. Mostafa, Y. Darwish, M. Moussa, Bull. Soc. Chim. (2) (1987) 216.

3. S. Zakvi, G. Metha, J. Electrochem. Soc., India 37 (1988) 237.

4. S. Hettiarachchi, Y. Chan, R. Wilson, Jr. Agarwala, Corrosion 45 (1989) 30 .

5. Y. Jianguo, W. Lin, V. Otieno-Alegc, Schweinsberg, Corros. Sci. 37 (1995) 6.

6. E. Khamis, M. Ameer, N. Al-Andis, G. Al-Senani, Corrosion 56 (2000) 127.

7. $\quad$ K.W. Rattf, A.N. Yao, J. Org. Chem. 31 (1966) 1185.

8. Y. Matsuda, K. Kucakabe, H. Yaneyama, I. Ikeda, S. Kamari, H. Tomura, Corros. Sci. 12 (1972) 93.

9. L. Heiss, M.Hille, (Farbwerke Hoechst AG). U.S.Pat.3. 773.675 (Nov. 20, 1973) (Chem. Abs., 80,148130 (1974)).

10. W.W. Frenier, W.J. Settineri , (Dow Chem. Co.); (a) U. S.Pat. 3.764 .543 (Oct. 9, 1973) (Chem. Abs., 80,86674 (1974)); (b) U.S. Pat. 3.969.414 (July13,1976) (Chem. Abs.85, 123665(1976)).

11. W.J. Settineri, W.W. Frenier, J.R. Oswald, U.S.Pat.3.996.147 (Dec.7, 1967) (Chem. Abs ., 86,58948.(1977)).

12. C.J.M. Stirling, "The Chemistry of the Sulphonium Group", Ed. by John Wiley and Sons Limited (1981).

13. A.M. Farag, M.S. Algharib, Org. Prep. and Proceed. Int . 20 (1988) 251.

14. S.T. Arab, B.A. El-Nabey, International J. Chem. 2 (1991) 23.

15. S.T. Arab, E.A. Noor, Corros. Sci. 35 (1993) 122.

16. F. Mylius, S. Nithen, J. Amer. Chem. Soc. 79 (1957) 1966.

17. A. Mazhar, S. Arab, E. Noor, J. App. Electrochem. 31 (2001) 1131.

18. S. Rengamani, T. Vasudevan, S.V. Iyer, Indian J. Technol. 31 (1993) 519.

19. S. Rengamani, S. Muralidharan, M.A. Kulandainathan, S.V. Iyer, J. App. Electrochem. 24 (1994) 355.

20. G.A. El-Mahdy, S.S. Mahmoud, Corrosion 51(6) (1995) 436.

21. R.J. Meakins, J. Appl. Chem. 13 (1963) 339.

22. H. Yamaoka, H. Fischer, Electrochim. Acta 10 (1965) 676.

23. R. Narayan, K.C. Pillai, Trans. Soc. Advan. Electrochem. Sci. Technol. 7(2) (1972) 63.

24. K.C. Pillai, R. Narayan, J. Electrochem. Soc. 125 (9) (1978) 1393.

25. S. Rengamani, S. Muralidharan, M. Ganesan, S.V. Iyer, Indian J. Chem. Technol.1 (1994) 168.

26. C.A. Mann, Trans. Electrochem. Soc. 69 (1936) 105.

27. L.I. Antropov, First Int. Cong. Metal Corros., Butterworths, London, 147 (1963). 
28. F.d' Yvoire, Bull. Soc. Chem. France 82 (1961) 2277 in "Comprehensive Inorganic Chemistry" , J.C. Bailar Jr., H.J. Emeleus, F.R.S., SIR. Ronald Nyholm, F.R.S. and A.F. Trotman Dickenson, Cardiff, No.2, 506 (1973).

29. L.P. Hammett, "Physical Organic Chemistry", McGraw-Hill, New York, (1940).

30. F.M. Donahue, K. Nobe, J. Electrochem. Soc. 112 (1965) 886.

31. Z.S. Smialowska, M. Kaminski, Corros. Sci. 13 (1973) 1.

32. S. Vasseghi, K. Nobe, Corrosion 35 (1979) 300.

33. M.M. Singh, A. Gupta, Bull. Electrochem. 12(9) (1996) 511.

34. A.El-Awady, B.A.A. El-Nabey, S.G. Aziz, M. Khalifa, H.Al-Ghamedy, Int. J. Chem. 1 (1990) 169.

35. J. Bastidas, J. Polo, E. Cano, G. Torres, J. Mater. Sci. 35 (2000) 2637.

36. A.El-Awady, B.A.A. El-Nabey, S.G. Aziz, J. Electrochem. Soc. 139 (1992) 2149.

37. J.O'M. Bockris, M.A.V. Devanathan, K. Muller, Proc. Royal Soc. 274 (1963) 55.

38. I. Langmuir, J. Am. Chem. Soc. 39 (1917) 1848.

39. J.O’M. Bockris, D. Drazic ,"Electrochemical Science", Taylor and Francis, London, 65 (1972).

40. M.N. Mousa, F.I. Taha, M.M. Gauda, G.M. Singab, Corros. Sci. 16 (1976) 379.

41. A.G. Gad Allah, N.N. Girgis, H. Moustafa, T.F. Mikhail, Hung. J. Industrial Chem. 23 (1995) 11.

42. S. Muralidharan, M.A. Quraishi, S.V. Iyer, Corros. Sci. 37(11) (1995) 1739.

43. S. Muralidharan, B.R. Babu, S.V. Iyer, J. App. Electrochem. 26 (1996) 291.

44. L. Heiss, M. Hille, (Farbwerke Hoechst AG). U.S. Pat.3. 675 (Now. 20, 1973) (Chem. Abs., 80, 148130 (1974)).

45. T. Tsuru, S.H.B. Gijutsu, J. Jpn. Soc. Corros. Eng. 27 (1978) 570.

46. K. Hladky, L.M. Callow, J.L. Dawson, Br. Corros. J. 15 (1980) 20.

47. F. Bentiss, M. Traisnel, M. Lagrenee, J. Appl. Electrochem. 31 (2001) 41. 